\title{
GROWTH OF IMMATURE DOUGLAS FIR BY TREE CLASSES'
}

\author{
BY J. W. KER²
}

Jobn William Ker was employed as Ranger Assistant and Assistant Ranger with the British Columbia Forest Service in the summers of 1935 through 1940. In 1941 be graduated with honors from the University of British Columbia, receiving the degree of Bacbelor of Applied Science in Forestry. Upon graduation Mr. Ker became a Forest Ranger with the B.C. Forest Service, transferring in 1945 to undertake mensurational investigations as an Assistant Forester in the Research Division, Victoria, B.C.

In 1948 be joined the Department of Forestry, University of British Columbia, as Assistant Professor of Forest Mensuration, wher a grant provided by the H. R. MacMillan Export Company. After a one-year leave-of-absence, in 1951 be received the degree of Master of Foresiry from Yale Scbool of Forestry. Professor Ker is now Associate Professor, Faculty of Forestry, University of British Colambia, and is a member of the Board of Examiners of the Association of British Columbia Foresters.

\section{ABSTRACT}

This report outlines the results of a test of the value of the TinneyMalmberg and the Schadelin systems of tree classification in estimating the growth rates of individual trees in second-growth stands of Douglas fir. Such tree classifications, that go beyond the recording of d.b.b. and crown class, are shoun to increase the accuracy of tree description, at least in terms of probable growth-rate. The auxiliary classifications, i.e., "crown-sides-free" and "crown quality", appear to be almost equally effective in reducing errors in estimates of the rate of diameter growth.

Multiple linear regressions were calculated to show the effect upon decadal radial-increment of the independent variables, d.b.h., crown class, and crown quality. Such relationships may provide (1) a guide to relative growth-rate of individual trees in drawing up tree-marking rules and (2) a basis for estimating gross current stand-growth.

During the normal course of development of a Douglas fir stand following clear cutting or fire, a relatively large initial number of seedlings is gradually reduced by natural competition and other causes. Early in the life of a stand certain trees gain dominance over their neighbors because of superior inherited qualities, an earlier start in life, or a more favorable local site. Others in the stand gradually fall behind in the struggle, become overtopped, and finally

\footnotetext{
1 Research Paper No. 3, Faculty of Forestry, University of British Columbia, Vancouver, B.C. 2 Associate Professor, Faculty of Forestry, University of British Columbia.

Acknowledgment is made to the forest industries of British Columbia who generously provided funds with which to initiate this research work. Further funds were provided by students of forestry, did valuable work as graduate assistants.
} 
die. Dominant trees with large healthy crowns are likely to be growing most rapidly and suppressed trees, receiving little direct light, most slowly. Usually a close relationship exists between the diameter of a tree and its current rate of growth, although the growth rate of a large tree might decrease as a result of competition or of failing health and vigor. Likewise, the growth rate of a small tree might increase because of reduced competition.

Although dominant trees generally grow faster in diameter, height, and volume than trees in the codominant and lower crown classes, there is considerable variation within a given crown class. In the more extreme cases, a healthy overtopped tree may show faster current diameter-growth than a much larger dominant or codominant tree. This can generally be ascribed to differences in the relative vigor and health of the crowns of the trees in question. A change in the current health of a tree will usually be followed by a gradual change in its crown class and size of crown; the tree may increase its growth or it may slow down depending on whether the change in current health is favorable or otherwise.

Recognizing the variation in growth rate or growth potential within a given crown class, foresters have attempted to improve their classification of trees by introducing another qualitative measure. To cite but two examples, Tinney and Malmberg (4) have used the "crown-sides-free" concept-the number of quadrants of the crown that are free to expand-, and Schadelin (3) has used "crown quality".

\section{The Tinney-Malmberg Classification}

Tinney and Malmberg (4) visualize the crown of the tree, projected on a horizontal plane, as divided into four quadrants or "sides". If all sides touch or almost touch the crowns of nearby trees or are overtopped by them, the tree is classified as a " $\mathrm{O}$ ". If one side or equivalent is free to expand, the tree is a " 1 ", and so on. This measure is combined with crown class expressed as "D" (dominant), "CD" (codominant), and "I" (intermediate). Suppressed trees are ignored as being a component that will disappear fairly soon from immature Douglas fir stands. A dominant tree with two sides free is classed as a "D-2" and the system is extended to all of the possible combinations of crown class and sides-free that exist in nature.

\section{The Schadelin Classification}

Schadelin (3) describes each tree by crown class using "100" for dominants, "200" for codominants, " 300 " for intermediates, and " 400 " for suppressed trees. To this he adds "10" for "good" stems, "20" for "average" stems, and " 30 " for "poor" stems, and " 1 " for "good" crowns, "2" for "average" crowns, and " 3 " for "poor" crowns. Thus, a codominant tree, 200 , with a good stem, 10, and an average crown, 2, would be classed as a 212. The number of combinations, each of which represent a tree class, is $36(4 \times 3 \times 3)$. For all practical purposes rate of growth usually can be assumed to be unaffected by stem quality, except in understocked stands in which 
excessive limbiness or heavy taper may be associated with rapid diameter growth.

Data collected during the course of a thinning project (1) at the University Forest near Haney, B.C., permitted a test of the usefulness of these two classifications in estimating the growth rates of individual trees in secondgrowth stands of Douglas fir and associated species. A large number of Douglas fir trees (516) were bored on two diametrically-opposite sides and radial-growth measurements were made. Each tree was classified by the two methods described above. For analysis, trees on sample plots of similar age and site quality were grouped. Three groups resulted: (i) 43 trees on Permanent Sample Plot (P.S.P.) 101 of average site index 140 and age 78 years; (ii) 455 trees on P.S.P.'s 102-107 inclusive and P.S.P. 109, of average site index 104 and age 65 years; and (iii) 18 trees on P.S.P. 108 of average site index 160 and age 56 years.

Preliminary graphic analysis of the data indicated that a strong, approximately linear, correlation exists between radial increment and (i) d.b.h., (ii) crown class, (iii) crown quality as estimated for the Schadelin classification, and (iv) crown-sides-free as determined for the Tinney-Malmberg classification. In order to show the relative usefulness of these four factors in assessing radial or diameter growth, multiple and partial correlation analyses were made. The degree of association of radial increment with each, as indicated by the square of the correlation coefficient expressed in per cent, is given in Table 1 for each of the first two groups of plots. Data from P.S.P. 108 were insufficient to justify analysis in this exploratory study.

TABLE 1.

EFFICIENCY, IN PER CENT, OF VARIOUS COMBINATIONS OF INDEPENDENT VARIABLES IN THE PREDICTION OF RADIAL INCREMENT

\begin{tabular}{|c|c|c|c|c|c|c|c|}
\hline \multicolumn{3}{|c|}{ Independent variables used } & \multicolumn{4}{|c|}{$\begin{array}{l}\text { Treo classification system } \\
\text { Tinney-Malnberg Schadelin }\end{array}$} & \\
\hline$D_{0} b_{0} h_{0}$ & $\begin{array}{l}\text { Crown } \\
\text { Class }\end{array}$ & $\begin{array}{l}\text { Crown } \\
\text { Quality }\end{array}$ & $\frac{P_{2} S_{2} P_{2} 101}{\text { Variabi }}$ & $\frac{102-109}{10 y \text { remov }}$ & $\frac{101}{\text { ed. pe }}$ & $\frac{102-109}{\text { cent }}$ & \\
\hline $\begin{array}{l}x \\
x \\
x\end{array}$ & $\begin{array}{l}x \\
x\end{array}$ & $\begin{array}{l}x \\
x \\
x\end{array}$ & $\begin{array}{l}83.9 \\
81.4 \\
79.2 \\
71.2\end{array}$ & $\begin{array}{l}96.4 \\
88.9 \\
91.6 \\
87.7\end{array}$ & $\begin{array}{l}95.0 \\
94.5 \\
86.5 \\
74.5\end{array}$ & $\begin{array}{l}96.7 \\
88.9 \\
85.0 \\
86.4\end{array}$ & $B 0+1$ \\
\hline & $\mathbf{x}$ & $x$ & & $\begin{array}{l}70.9 \\
57.0 \\
67.7\end{array}$ & & $\begin{array}{l}75.6 \\
76.5 \\
70.1\end{array}$ & $\begin{array}{l}\text { yorichlo } \\
\text { cank }\end{array}$ \\
\hline
\end{tabular}

Table 1 shows that radial increment can be estimated more accurately by the use of all three variables of either classification system than by the use of fewer. Similarly, two variables provided a more accurate estimate than does any single variable. Since all three variables of each classification system

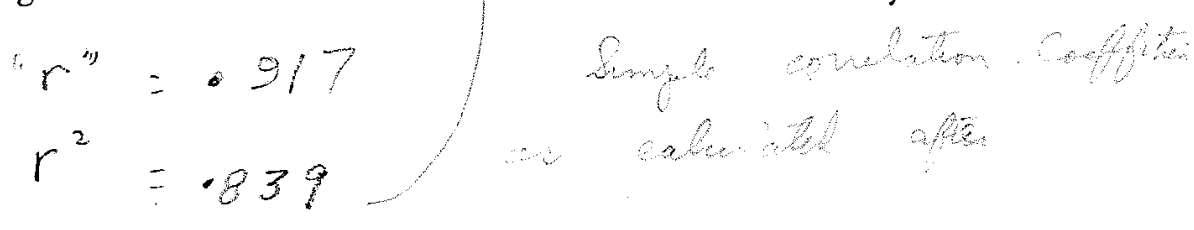


proved to have value, the relationships involved were expressed as multiple regression equations. Estimated decadal radial-increment by diameter and tree class are shown for P.S.P. 101 in Tables 2 and 3, and for P.S.P.'s 102-109 in Tables 4 and 5 .

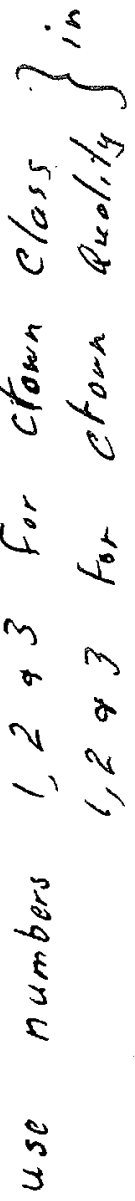

TABLE 2.

Decadal Radial Increment of Trees Classified by the Schadelor SYSTEM ON P.S.P. 101 (AGE 78 YEARS, SitTE INDEX 140).

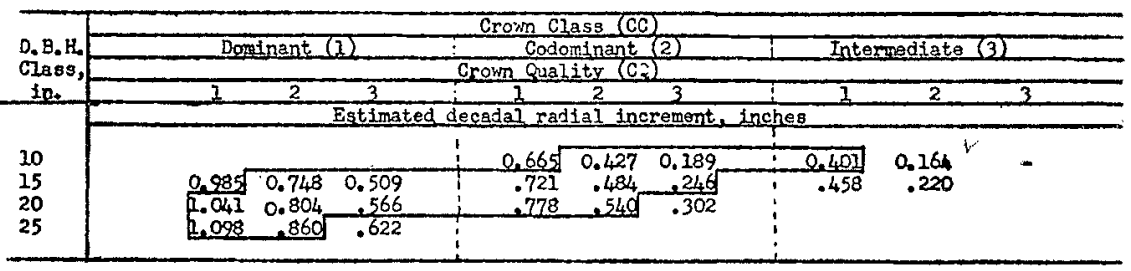

Block indicates extent of basic data. Tabular values were calculated using the regression equation: Increment $=0.657+0.0113$ (DBH- 17.442) -0.2635 (CC- 1.4884) -0.2379 (CQ 1.0585$)$.

TABLE 3.

Decadal Radial Incriment of Trees Classified by the TinneyMAlMberg System on P.S.P. 101 (AGE 78 years, Site INDEX 140).

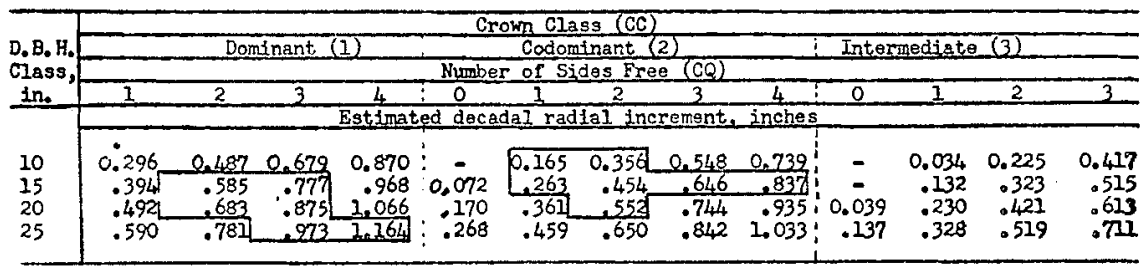

Block indicates extent of basic data. Tabular values pere calculated using the regression equation: Increment $=0.657+0.01965$ (DBH- 17.442) -0.13104 (CC- 1.465)

\section{TABLE 4.}

Decadal Radial Increment of Trees Classified by the Schadelin SYSTEM ON P.S.P. 102-109 (AGE 65 YEARS, SITE INDEX 104).

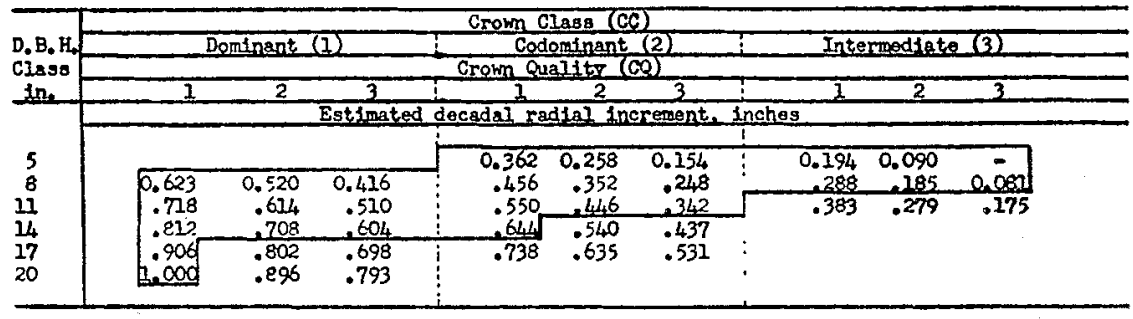

Block indicates extent of basic data. Tabular values were calculated uaing the regression equation: Increment $=0.4700+0.0314$ (DBH- 9.412) -0.1675 (CC- 1.6645) -0.1038 (CQ 1.832 ). 
TABLE 5 .

Decadal Radial Increment of Trees Classified by the TinneyMalmaerg System on P.S.P. 102-109 (AGE 65 years, Site INDEX 104).

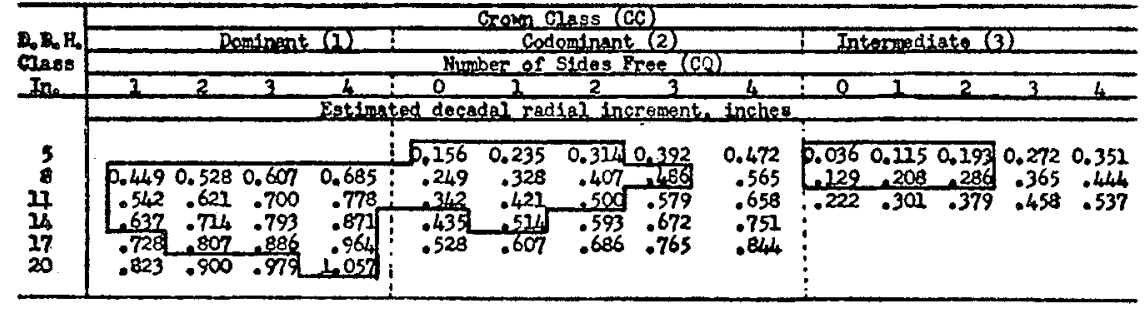

Block Indicates extent of basic data. Tabular values were calculated noing tho regression equation: Inerement $=0.4700+0.0810$ (DBH- 0.4120$)-0.1206$ (CC- 1.6645$)+0.0789$ (CQ 1.7800).

\section{CONCLUSIONS}

Fach of the variables used in the two classification systems is a useful indicator of the recent growth rate of individual trees in natural stands of Douglas fir. The most precise estimate of growth rate is obtained when all three factors are taken into account, in which case the correlation is high and the residual variation minimal.

Although d.b.h. is the only objective measure of the three factors involved in the tree classifications, the other two-crown class and crown quality in the Schadelin system, or crown class and crown-sides-free in the Tinney-Malmberg system-are readily assessed by a field man after some practice. Obviously, human error is involved in such subjective classifications, but guides can be drawn up for a given species and locality so as to minimize errors of classification. In this particular test, all trees were classified by the same man whose experience in such work had been quite limited. The consistency of the results obtained is illustrated by Figure 1. An erratic classification would be unlikely to result in such a close approximation to a "normal" frequency distribution.

\section{SUMMARY}

The findings reported herein may be summarized and interpreted as follows:

(1) A tree classification that goes beyond the recording of d.b.h. and crown class adds to the accuracy of tree description, at least in terms of probable growth rate.

(2) The auxiliary classifications tested, i.e., "crown-sides-free" and "crown quality", are almost equally effective in reducing errors in estimates of the rate of diameter growth.

(3) Using tree class as a guide to relative growth-rate of individual trees, a marking rule may be devised to remove any combination of slow, average, or fast-growing trees. Such a rule, tested on sample areas, can 


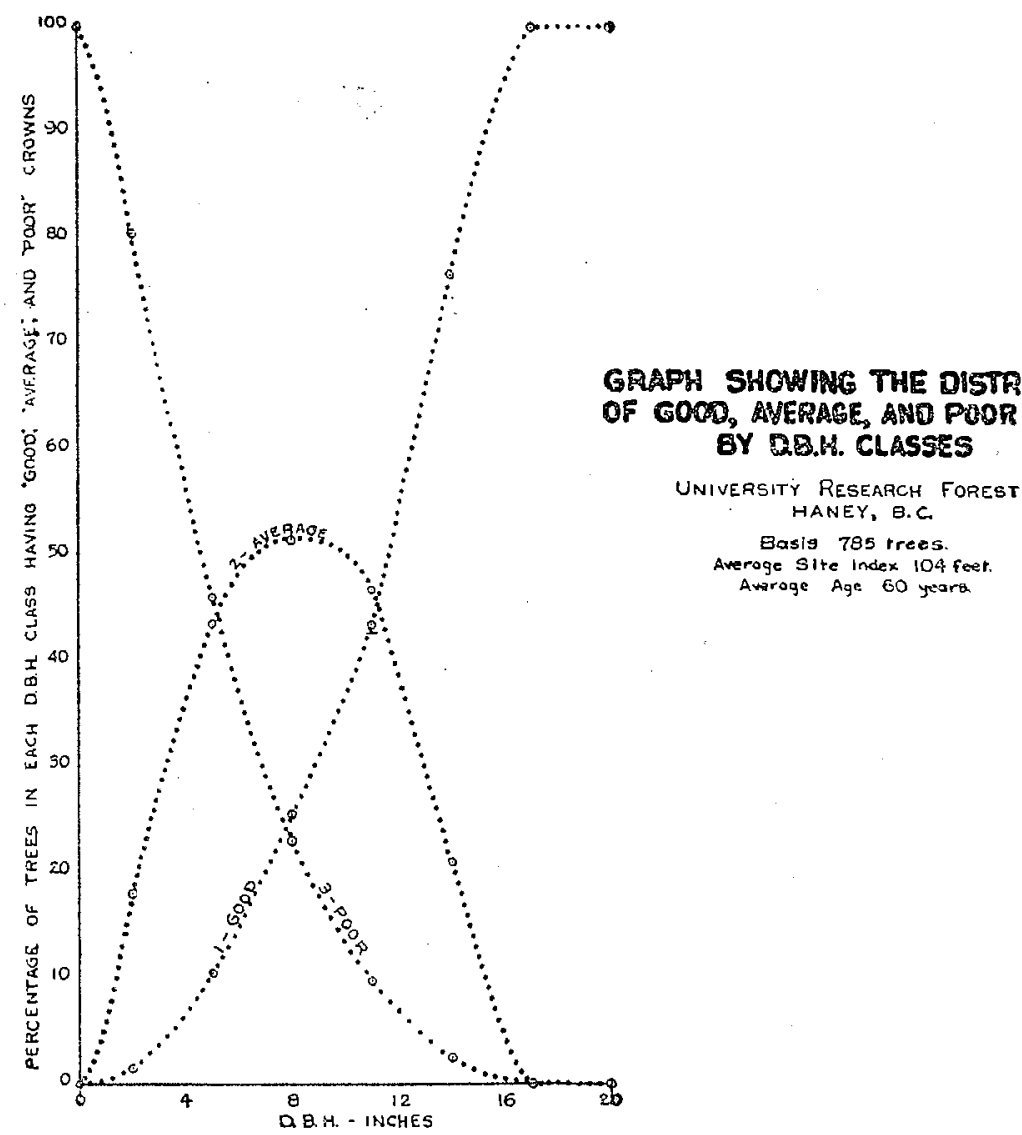

be modified in order to remove a given volume per acre from specified tree classes.

(4) Tree classification does not indicate necessarily which of the trees would benefit most by release in a thinning or partial cutting. Tinney and Malmberg (4) have shown the trend of growth following release for their tree classes.

(5) The findings provide a basis for estimating gross current growth in volume for stands in which adequate samples have been studied for diameter growth by tree classes. An estimate of this kind is probably more accurate than one based upon a stand-projection method in which only d.b.h. is considered. In order to convert diameter growth to volume growth, data for height growch are required; these may be obtained, 
to the degree of accuracy needed, from yield tables or from sample-plot records if these are available.

(6) In order to estimate net growth, mortality must be known or estimated. In stands that are to be thinned, however, gross and net growth may be practically equal over short periods because of greatly reduced mortality following thinning. For example, on P.S.P. 101 gross increment for the decade 1939-48 was estimated to be 1370 cubic feet per acre, according to stand projection based upon tree classification, compared to an actual gross growth of approximately 1500 cubic feet per acre. Alternatively, using yield-table values (2) and assuming no change in normality, net growth for the same period would be predicted to be 880 cubic feet per acre. It is likely that the growth rate following a thinning that anticipates mortality will be closer to the gross growth as estimated by the method described herein than it will be to the net growth as determined from appropriate yield tables.

\section{REFERENCES Cited}

1. ALLEN, GEORGE S. 1950. Forest Research at the University of British Cclumbis Faculty of Forestry, University of British Columbia, Research Note 1. (Reprinted from the British Columbia Lumberman, December 1950).

2. British Columbia Forest Service. 1947. Yield tables. Mimeo. Victoria, B.C.

8. HAWLEY, RALPH C. 1946. The practice of silviculture. Fifth edition, p. 218. John Wiley and Sons, New York.

4. TINNEY, WILLIAM A., and DONALD B. MALMBERG. 1948. Tree management and marking rules, second growth Douglas fir. University of Washington, College of Forestry, and Skagit Forest Council, Sedro Woolley, Washington. $33 \mathrm{pp}$.

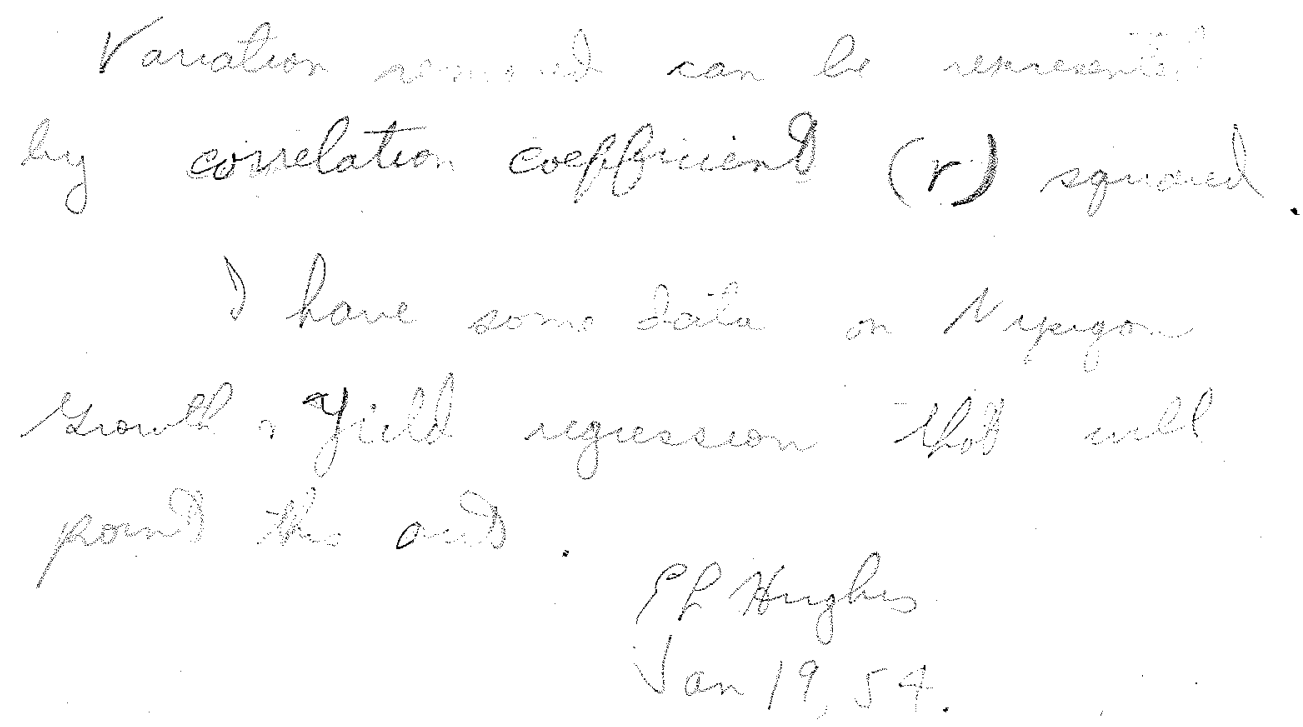

